ISSN 0103-5150

Fisioter. Mov., Curitiba, v. 29, n. 3, p. 469-476, Jul./Set. 2016

Licenciado sob uma Licença Creative Commons

DOI: http://dx.doi.org.10.1590/1980-5918.029.003.A004

(c)

\title{
Diabetic footwear: is it an assistive technology capable of reducing peak plantar pressures in elderly patients with neuropathy?
}

\author{
Calçado para diabético: uma tecnologia assistiva capaz de \\ reduzir os picos de pressão plantar de idosos com neuropatia?
}

\author{
Alexandre Faraco de Oliveira ${ }^{[a]}$, Ana Carolina Bertoletti De Marchi $^{[b]}$, Camila Pereira Leguisamo ${ }^{[b] *}$ \\ [a] Universidade do Planalto Catarinense (UNIPLAC), Lages, SC, Brazil \\ [b] Universidade de Passo Fundo (UPF), Passo Fundo, RS, Brazil
}

\section{Abstract}

Introduction: Diabetes Mellitus is a chronic disease with high prevalence in the population in particular among the elderly. The longer time of diabetes, increased the chances of developing complications such as peripheral neuropathy, which is an important factor in the genesis of plantar lesions by changing the distribution and formation of plantar pressure peaks. Objective: Evaluate the influence of an Assistive Technology, therapeutic footwear for diabetics, in the peaks of plantar pressure of elderly. Methods: This was an experimental study of transversal type, composed by 10 elderly, diabetic, with peripheral neuropathy, using as an instrument to measure a baropodometry platform. Were measured peaks of plantar pressure, static and dynamic in three situations: barefoot, the participants' own standard footwear and with therapeutic footwear for diabetics. Data analysis by normal distribution as a single paired sample, applying the ANOVA test. Results: The use of therapeutic footwear for diabetics promoted a reduction in media of peak plantar pressure in the order of $22 \%$ in static analysis, and $31 \%$ in dynamic analysis. Conclusion: The therapeutic footwear for diabetics was able to produce significant reductions in peak plantar pressure,

\footnotetext{
*AFO: MS, e-mail: afaraco@gmail.com ACBDM: PhD, e-mail: carolina@upf.br CPL: MS, e-mail: camila@upf.br
} 
being more efficient than a common footwear. This effect may contribute to the prevention of injuries associated with the diabetic foot.

Keywords: Aging. Diabetic Foot. Diabetic Neuropathies.

\section{Resumo}

Introdução: $O$ Diabetes Mellitus é uma doença crônica de elevada prevalência na população em especial entre os idosos. Quanto maior o tempo de diabetes maiores as chances de desenvolver complicações como a neuropatia periférica, importante fator na gênese de lesões plantares por alterar a distribuição e formação de picos de pressão. Objetivo: Avaliar a influência de uma Tecnologia Assistiva, o calçado para diabético, nos picos de pressão plantar de idosos. Métodos: Estudo experimental do tipo transversal, composto por 10 idosos, diabéticos, com neuropatia periférica, utilizando como instrumento de medida uma plataforma de baropodometria. Foram aferidos picos de pressão plantar, de forma estática e dinâmica, em três situações: descalço, com calçado de uso do paciente e com calçado para diabético. Análise por distribuição de normalidade, como única amostra pareada, aplicando-se o teste ANOVA. Resultados: A utilização do calçado para diabético promoveu uma redução na média dos picos de pressão plantar na ordem de $22 \%$ na análise estática, e de $31 \%$ na análise dinâmica. Conclusão: $O$ calçado para diabético foi capaz de produzir reduções significativas nos picos de pressão plantar, sendo mais eficiente que um calçado comum. Este efeito pode contribuir na prevenção de lesões associadas ao pé diabético.

Palavras-chave: Envelhecimento. Pé Diabético. Neuropatias Diabéticas.

\section{Introduction}

The diabetic patient's foot is exposed to a number of neuropathic changes. Such changes work synergistically and lead to greater propensity to develop skin lesions of difficult healing, fact that expose the patient to the risk of often developing severe infections. Diabetic neuropathy affects sensory, motor and autonomic aspects that together turn this complication more harmful. Sensory damage can cause the patient not to feel the lesion, so it develops to the point of forming ulcers $(1-3)$.

The deformities caused by the imbalance in the intrinsic foot muscles along with the lack of sensitivity lead to the rearrangement of the support that the sole of the foot has on the ground. These deformities sometimes form high-pressure areas that are susceptible to lesions (4) and, because of such lesions, every 30 seconds a lower limb amputation related to diabetes is done (5). Over $85 \%$ of these amputations are preceded by ulcers, and ulcers are related to neuropathies in more than $90 \%$ of the cases (6).

Different technological resources can be used to redistribute these plantar pressures, such as insoles and diabetic footwear. In the last years, these and other resources started to be called Assistive Technologies (AT) due to the understanding that they promote people's autonomy by providing them independence and protection.

Losing part of the body brings multiple consequences for the diabetic individual. Not only the limitations and restrictions in performing activities of daily living and basic personal care but also the emotional losses associated with different degrees of dependency that are often caused by amputations and the negative feelings associated with it (7).

The understanding of the extent of the problem and the different ways of acting in order to minimize it tend to grow in the years to come. Type II diabetes becomes more prevalent with aging and ulcerations are related to diabetes' duration, therefore, elderly patients are the most affected by ulcerations and amputations $(8,9)$. In addition, there is the fact that the elderly tend to develop limitations besides those caused by amputations (10). Finally, the number of elderly across the planet is growing and this trend is expected to intensify in the next decades (11).

The current study aims to assess a device that may be used to prevent diabetic foot lesions. Therefore, plantar pressure was statically and dynamically measured in a group of diabetic elderly with peripheral neuropathy. The impact of an AT, namely the diabetic footwear, on these plantar pressures was also measured. 


\section{Methods}

This is an experimental cross-sectional study consisting of over-60-year-old patients with type II diabetes, who have shown no foot ulcerations or deformities and who were able to walk without the need for support or assistance. After they agreed to participate in the study, these patients were diagnosed for the presence of peripheral neuropathy.

Initially, patients were assessed according to personal data: gender, age, diabetes duration, weight, height and foot size. Peripheral neuropathy diagnosis was conducted according to the Neuropathy Symptom Score by Moreira (12). The individuals included in the study underwent plantar pressure measurement, statically and dynamically performed, according to three conditions: barefoot patients, patients wearing their own footwear and wearing the diabetic footwear (Figures 1, 2 and 3).

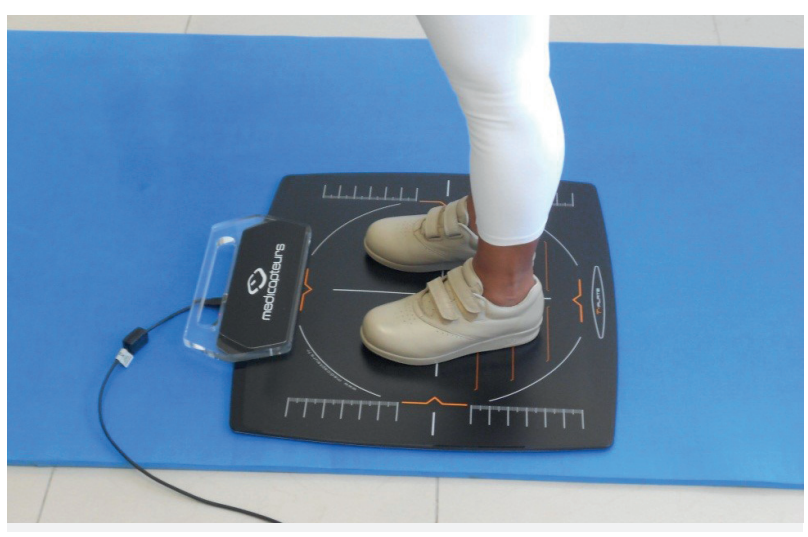

Figure 1 - Baropodometry platform being used for the measurement of the static plantar pressure with the use of footwear for diabetic foot.

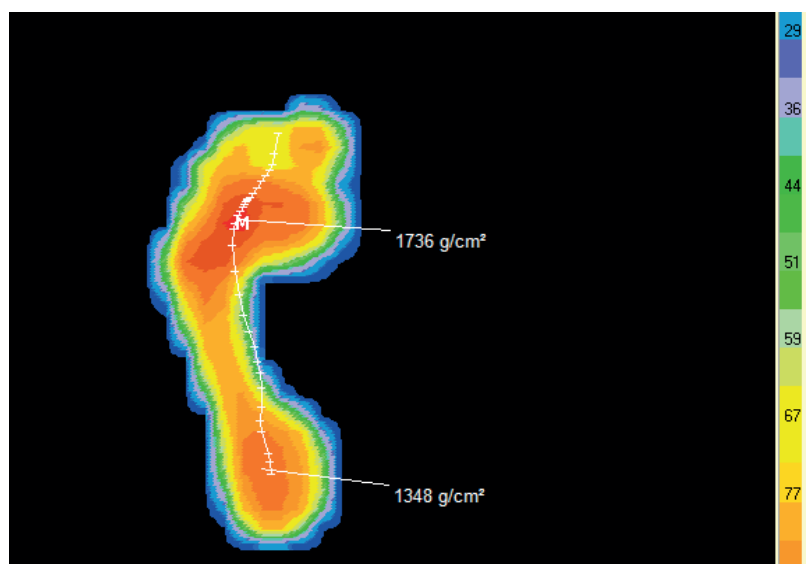

Figure 2 - Results of dynamically measured of peak plantar pressure left foot barefoot.

Color matching to points of less pressure in blue, until the points with the highest pressure in red, as scale right of figure. Trace evidencing the plantar movement is not related to the pressure rating.

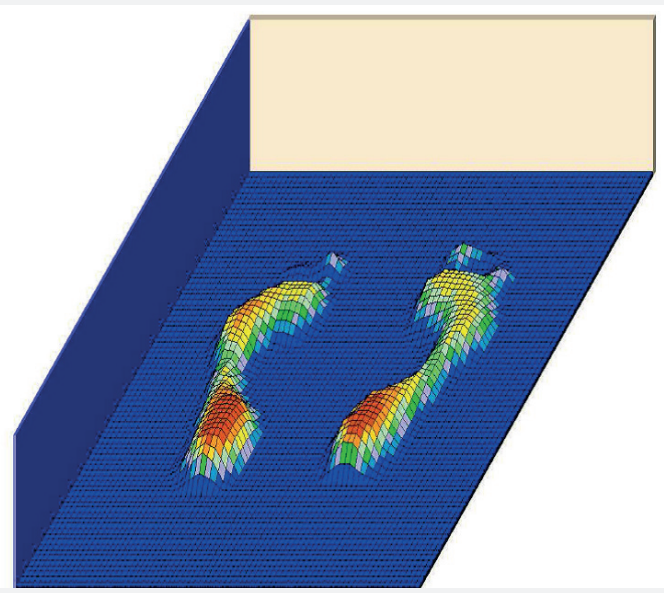

Figure 3 - The measuring result of the peaks of plantar pressure, static measurement, patient barefoot in 3D representation. Color matching to points of less pressure in blue (represented by the parties with mild elevation, base and areas without pressure) and the points with the highest pressure is in red (peak of the elevations).

A T-Plate model platform, manufactured by Medicapteurs ${ }^{\circledR}$ was used to measure the plantar pressure. The platform size is of $610 \times 580 \mathrm{~mm}$, with thickness of $10 \mathrm{~mm}$. It uses 1,600 resistance sensors that measure minimum pressure of $0.4 \mathrm{~N}$ and maximum pressure of $100 \mathrm{~N}$ and it has image acquisition frequency higher than 100 frames per second (13).

Data collection was done as follows: after the patients had their neuropathy measured and their foot inspected, they were asked to walk barefoot by stepping on the platform repeatedly, to the point that the walking movement happened naturally. The patient's walk was monitored and observed by one of the researchers. Simultaneously, another researcher watched the capture of real-time images on the monitor that received the information. At least 10 and at most 20 walks for each foot, of each patient, were necessary in order to collect the data. After capturing the dynamic data, patients were asked to remain standing on the platform without making any movement for 30 seconds, time needed to get the static data. Only one take was necessary to get the data from each patient. Then, the same procedures were repeated with patients wearing their own footwear first, and then the diabetic footwear.

Data analysis was done by the SPSS software to find the mean and standard deviation values. The data were explored as a single paired sample by 
distribution normality, applying the ANOVA (oneway ANOVA) test for repeated measures. The sample size estimate was predetermined according to a recently published study that also sought to compare peak plantar pressures in diabetic patients with neuropathy using plantar devices such as insoles or footwear (6).

Using $\alpha=5 \%$ and $90 \%$ power, the required sample size would be of 04 individuals given as a single independent paired sample. It was decided that a larger sample of 10 individuals ( 20 feet) would be used - in addition to observing similar studies with samples from 8 to 20 individuals - in order to ensure the importance of the study, since a magnitude of smaller effect is clinically significant.

The current study was submitted to the Research Ethics Committee evaluation, by Brazil platform, and it was approved under the CAAE number: 10759712.7.0000.5342.

\section{Results}

The group of 10 patients was predominantly comprised by eight women, all of them over their 60s, ranging from 61 to 72 years. In addition, all patients had diabetes for more than ten years, but not more than twenty years.

Through this analysis, we were able to investigate the plantar pressure distribution and to statically and dynamically measure the maximum plantar pressure values in the following different situations: barefoot, patients wearing their own footwear and the diabetic footwear.

The higher peak plantar pressures were found in barefoot patients in both static and dynamic analyses, with gradual reduction in the values. First, there was mild reduction when patients wore regular footwear, and then there was greater reduction when they wore diabetic footwear (Table 1).

Table 1 - Comparison of peak plantar pressure, barefoot, with the patient own footwear

\begin{tabular}{|c|c|c|c|c|}
\hline $\begin{array}{l}\text { Peak plantar pressure } \\
\text { (PPP) }\end{array}$ & Barefoot & Own footwear & Diabetic footwear & P value* \\
\hline $\begin{array}{l}\text { Statically measure } \\
\text { (two feet } / n=20 \text { ) }\end{array}$ & $599.90 \pm 84.15$ & $573.90 \pm 88.44$ & $463.60 \pm 69.23$ & $<0.001$ \\
\hline $\begin{array}{l}\text { Dynamically measure } \\
\text { (two feet } / \mathrm{n}=20 \text { ) }\end{array}$ & $1284.85 \pm 204.42$ & $1214.30 \pm 214.37$ & $885.80 \pm 134.36$ & $<0.001$ \\
\hline $\begin{array}{l}\text { Statically measure } \\
\text { (right foot / } n=10 \text { ) }\end{array}$ & $604.60 \pm 100.43$ & $517.90 \pm 97.48$ & $462.60 \pm 65.75$ & 0.009 \\
\hline $\begin{array}{l}\text { Statically measure } \\
\text { (left foot } / n=10 \text { ) }\end{array}$ & $595.20 \pm 69.38$ & $575.90 \pm 83.68$ & $464.60 \pm 76.12$ & 0.015 \\
\hline $\begin{array}{l}\text { Dynamically measure } \\
\text { (right foot } / n=10 \text { ) }\end{array}$ & $1181.70 \pm 152.52$ & $1182.60 \pm 224.79$ & $836.10 \pm 125.60$ & $<0.001$ \\
\hline $\begin{array}{l}\text { Dynamically measure } \\
\text { (left foot } / n=10 \text { ) }\end{array}$ & $1388.00 \pm 203.25$ & $1246.00 \pm 186.71$ & $935.50 \pm 129.79$ & $<0.001$ \\
\hline
\end{tabular}

Note: Values are expressed mean \pm standard deviation.

* Test of Analysis of Variance (ANOVA) for repeated measures 
In the static measurement, the highest peak plantar pressure values in barefoot patients were on average $599.90 \mathrm{~g} / \mathrm{cm}^{2}$. The use of the patient's own footwear produced a $4.3 \%$ reduction. On the other hand, the diabetic footwear was able to produce an average reduction of approximately $22 \%$ in the measured peak plantar pressure values, thus reaching $463.60 \mathrm{~g} / \mathrm{cm}^{2}$ on average (Table 2).

The dynamic measurement also found the highest peak plantar pressure values in barefoot patients, $1284.85 \mathrm{~g} / \mathrm{cm}^{2}$ on average. The use of the patient's own footwear caused a $5.5 \%$ reduction in peak plantar pressures. On the other hand, the diabetic footwear caused an average reduction of $31 \%$ in peak plantar pressures, thus reaching $885.80 \mathrm{~g} / \mathrm{cm} 2$ (Table 2).

Table 2 - Absolute and relative mean difference of peak plantar pressure comparing barefoot, patient own footwear and diabetic footwear $(n=20)$

\begin{tabular}{|c|c|c|}
\hline & $\begin{array}{l}\text { Absolute } \\
\text { difference } \\
\text { (IC 95\%) }\end{array}$ & $\begin{array}{c}\text { Relative } \\
\text { difference } \\
\%\end{array}$ \\
\hline \multicolumn{3}{|l|}{ Static } \\
\hline $\begin{array}{l}\text { Barefoot - Patient own } \\
\text { footwear }\left(\mathrm{g} / \mathrm{cm}^{2}\right)\end{array}$ & 26 & 4.3 \\
\hline $\begin{array}{l}\text { Patient own footwear - } \\
\text { Diabetic footwear }\left(\mathrm{g} / \mathrm{cm}^{2}\right)\end{array}$ & 111.3 & 19.2 \\
\hline $\begin{array}{l}\text { Barefoot - Diabetic footwear } \\
\left(\mathrm{g} / \mathrm{cm}^{2}\right)\end{array}$ & 136.3 & 22.7 \\
\hline \multicolumn{3}{|l|}{ Dynamic } \\
\hline $\begin{array}{l}\text { Barefoot - Patient own } \\
\text { footwear }\left(\mathrm{g} / \mathrm{cm}^{2}\right)\end{array}$ & 70.55 & 5.5 \\
\hline $\begin{array}{l}\text { Patient own footwear - } \\
\text { Diabetic footwear }\left(\mathrm{g} / \mathrm{cm}^{2}\right)\end{array}$ & 328.5 & 27 \\
\hline $\begin{array}{l}\text { Barefoot - Diabetic footwear } \\
\left(\mathrm{g} / \mathrm{cm}^{2}\right)\end{array}$ & 399.0 & 31 \\
\hline
\end{tabular}

Note: Average values are expressed.

The overall data analysis showed significant difference when comparing the peak plantar pressure values between the following situations: barefoot patient and patient wearing diabetic footwear. The dynamic analysis found difference when both feet were analyzed together and when they were analyzed individually. The static analysis found more significant difference when both feet were analyzed together (Table 1).

In summary, we could observe that in all situations tested there was a progressive reduction of the peak of plantar pressures, is in static or dynamic assessment, when the use of shoes. The common footwear, for use of the patient has already produced some effect, however was the use of diabetic footwear which determined the reductions of significant pressure.

\section{Discussion}

Diabetes Mellitus (DM) is a disease caused by metabolic disorders characterized by hyperglycemia resulting from defects in insulin secretion or action. The vast majority of patients, more than $90 \%$, has type II diabetes, which typically affects over-40-yearold individuals and its incidence increases with age $(3,14)$.

Currently, DM has been seen as an epidemic in the world. Since it is a chronic disease related to aging, the increasing life expectancy in different populations has led to a growing number of elderly and diabetic patients (15). In Brazil, the number of diabetic individuals in the population is estimated between 12 and $13.5 \%$. If only over-60-year-old individuals are taken under consideration, the number of diabetic individuals in the population will be around $17.5 \%$ $(16,17)$. As individuals start living longer with diabetes, the chances of developing complications related to the disease grow. Among these complications, the so-called diabetic foot is the most frequent and feared because it represents higher risk of amputations and death $(1,2)$.

Although population studies on diabetic foot are rare in Brazil, a survey conducted in primary care services identified $9 \%$ of individuals with diabetic foot among diabetic patients, with significant prevalence among the elderly population (18). Such prevalence is related to the bigger number of complications in the population living longer with diabetes, and these complications are involved in the genesis of the lesions. Usually, the neuropathy is clinically detected in at least $50 \%$ of the diabetic patients after 10 years of disease. However, if more sensitive detection methods are used, such prevalence gets close to $100 \%$. Thus, elderly individuals who normally have diabetes for over a decade usually have different degrees of 
peripheral neuropathy that will remain throughout their lives $(19,20)$.

A recent review showed that among the many factors that can act in the genesis of plantar lesions, four stand out: peripheral neuropathy, peripheral vascular disease, foot deformities and lesion or previous amputation (21). The neuropathic alterations tend to change the plantar pressure distribution by concentrating it in inappropriate places and at loads higher than those the skin can withstand, thus facilitating the emergence of lesions $(22,23)$.

Although the gait of patients with diabetic neuropathy may present several modifications, not all of them are fully understood. It is known that peak plantar pressures over $6 \mathrm{~kg} / \mathrm{cm} 2$ are predictive of lesion (24). Even if they do not reach elevated values, the motor neuropathy's typical changes, such as "claw" fingers, added to sensory neuropathy and the consequent loss of protective sensation lead to a condition that results in skin lesions (3).

The plantar pressure redistribution can be forced by devices such as insoles and footwear. They reduce peak pressures and may influence the emergence of lesions $(4,22,25)$. Two recent studies sought to assess devices that act on plantar pressure.

The study by Raspovic (23) found the ability of a particular insole-type device to reduce plantar pressure when comparing it with other types of protection, such as footwear. The result showed to be positive, since - besides the fact that it could be placed in different types of footwear - the insole was able to reduce the peak plantar pressure values by up to $51 \%$.

The study by Paton (26) aimed to compare two types of insole-type assistive technologies, a manufactured one and another specially customized for the patient. The patients participating, were considered neuropathy by submit amendment sensory in test with the 10-g monofilament and shaking in benchmarking with the diapason of $128 \mathrm{~Hz}$. The authors found no significant differences between these devices effect on the plantar pressure, both being effective in the reduction of peaks between 22 to $27 \%$, but the customized insole had the disadvantage of being more expensive.

The current study aimed to test the diabetic footwear as an equipment-type assistive technology used in an attempt to prevent lesions in the feet of diabetic patients by assessing its action specifically on plantar pressure.
It can be said that, according to static and dynamic measurements, the diabetic footwear produced significant reductions in the peak plantar pressures and that the regular footwear usually used by the patients was not able to provide the same effect. Thus, there is gain in using a specific device over the use of a regular footwear and over walking barefoot.

However, there was no standardization in the type or model of regular footwear, since the current study did not aim to compare the two types of footwear, but only to test whether the diabetic footwear would redistribute plantar pressure.

Although it seems logical, one cannot say that this effect would be able to prevent the formation of lesions in this or other groups. Only by the longterm use of the device as well as by the monitoring of patients, it is possible to measure this type of undesirable skin lesions, which are not only related to plantar pressure.

The different resources and methods understood as AT aim to act as factors capable of providing autonomy. The elderly group is one of the target groups, since natural aging is a factor that generates multiple dependencies. Elderly diabetic patients show lower functional capacity when compared with non-diabetic ones (10). Even among diabetic patients, those with plantar lesions usually show more unfavorable evolution (1).

An AT, such as the diabetic footwear, able to act on plantar pressure by attenuating the peak pressures can be useful in order to allow diabetic elderly patients, even those with neuropathy, to have more freedom to walk and to be less exposed to skin lesions and to all the consequences resulting from them $(27,28)$. These devices applied in combined form the other prevention practices have their action potentized in a strategy of continued care with the feet of diabetic patients (29-31).

\section{Conclusion}

The use of footwear by elderly diabetic patients with neuropathy is beneficial to reduce the peak pressures their feet are subjected to. The diabetic footwear, when compared with the regular footwear commonly used by the patients, was more effective in reducing plantar pressure. Both the individual analysis of each foot and together, either static or dynamic analysis, strengthening the 
conviction that this AT is useful in reducing peak of plantar pressures.

Although we can infer that the reduction of the peak of plantar pressures will impacting on the genesis of plantar lesions, clinical studies are required with follow up broad to determine if and to what extent this action on plantar pressure will be effective in reducing the incidence of plantar lesions of these patients.

\section{References}

1. Lipsky BA. Expert opinion on the management of infections in the diabetic foot. Diabetes Metab Res Rev. 2012;28:163-78.

2. Hobizal KB, Wukich DK. Diabetic foot infections: current concept review. Diabet Foot Ankle. 2012;1:01-8.

3. Diretrizes da Sociedade Brasileira de Diabetes 2009 / Sociedade brasileira de diabetes. 3rd ed. Itapevi, (Brazil): A. Araújo. Silva Farmacêutica; 2009. 400p. Portuguese.

4. Cavanagh PR, Bus SA. Strategies to Prevent and Heal Diabetic Foot Ulcers: Off-loading the Diabetic Foot for Ulcer Prevention and Healing. J Am Podiatr Med Assoc. 2010;100(5):360-8.

5. Gershater M, Löndahl M. Complexity of factors related to outcome of neuropathic and neuroischaemic/ischaemic diabetic foot ulcers: a cohort study. Diabetologia. 2009;52(3):398-408.

6. Boulton AJM, Vileikyte L, Ragnarson-Tennvall G, Apelqvist J. The global burden of diabetic foot disease. Lancet. 2005;366(9498):1719-24.

7. Beattie AM, Campbell RVK. "What ever I do it's a lost cause." The emotional and behavioural experiences of individuals who are ulcer free living with the threat of developing further diabetic foot ulcers: a qualitative interview study. Health Expect. 2012;17(3):429-39.

8. Apelqvist J. The foot in perspective. Diabetes Metab Res Rev. 2008;24:110-5.

9. Kesavadev JD, Short KR, Nair KS. Diabetes in old age: an emerging epidemic. J Assoc Physicians India. 2005;51:1083-94.
10. Souza NMG, Honorato SMA, Xavier ATF. Vision of the world, cultural and environmental concept care: the care of the elderly with diabetes mellitus. Rev Gaucha Enferm. 2012;33(1):139-46.

11. Instituto Brasileiro de Geografia e Estatística. Projeção da população do Brasil por sexo e idade 1980-2050: revisão 2004 [Projection of the Brazilian population by sex and age, 1980-2050: 2004 revision]. Rio de Janeiro: IBGE; 2004.

12. Moreira RO, Castro AP, Appolinário JC, Ellinger VCM, Coutinho WF, Zagury L. To the Portuguese translation and assessment of the reliability of a scale for the diagnosis of diabetic Distal Polyneuropathy. Arq Bras Endocrinol Metab. 2005;49(6):944-50.

13. Medicapteurs. T-Plate Install Manual Version 2.0. 2012 [cited 2013 Mar 10].

Available from: http://tinyurl.com/zlqeflg.

14. Gambert SR, Pinkstaff S. Emerging Epidemic: Diabetes in Older Adults: Demography, Economic Impact, and Pathophysiology. Diabetes Spectrum. 2006;19(4):221-8.

15. Yang SH, Dou KF, Song WJ. Prevalence of diabetes among men and women in China. $\mathrm{N}$ Engl J Med. 2010;24(25):2425-6.

16. Bosi PL, Carvalho AM, Contrera D, Casale G, Pereira MA, Gronner MF, et al. Prevalence of diabetes mellitus and impaired glucose tolerance in the urban population of 30 the 79 years of the city of São Carlos, São Paulo. Arq Bras Endocrinol Metab. 2009;53(6):726-32.

17. Alves LC, Leimann BCQ, Vasconcelos MEL, Carvalho MS, Vasconcelos AGG, Fonseca TCO, et al. The influence of the chronic diseases in the functional capacity of the elderly of the city of São Paulo, Brasil. Cad Saude Publica. 2007;23(8):1924-30.

18. Vieira-Santos ICR, Carolina M, Costa W, Gabrielle M, Nóbrega DL. Prevalence of diabetic foot and associated factors in the family health units in the city of Recife, Pernambuco, Brazil in 2005. Cad Saude Publica. 2008;24(12):2861-70.

19. Uccioli L. Prevention of diabetic foot ulceration: new evidences for an old problem. Endocrine. 2013;44(1):3-4. 
20. Gale L, Vedhara K, Searle A, Kemple T, Campbell R. Patients' perspectives on foot complications in type 2 diabetes: a qualitative study. Br J Gen Pract. 2008;58(553):555-63.

21. Monteiro-Soares M, Boyko E, Ribeiro J, Ribeiro I, Dinis-Ribeiro M. Predictive factors for diabetic foot ulceration: a systematic review. Diabetes Metab Res Rev. 2012;28(07):574-600.

22. Waaijman R, Bus SA. The interdependency of peak pressure and pressure-time integral in pressure studies on diabetic footwear: no need to report both parameters. Gait Posture. 2012;35(1):1-5.

23. Raspovic A, Landorf KB, Gazarek J, Stark M. Reduction of peak plantar pressure in people with diabetes-related peripheral neuropathy: an evaluation of the DH Pressure Relief ShoeTM. J Foot Ankle Res. 2012;5(25):15-25.

24. Maciejewski ML, Reiber GE, Smith DG, Wallace C, Hayes S, Boyko EJ. Effectiveness of diabetic therapeutic footwear in preventing reulceration. Diabetes Care. 2004;27(7):1774-82.

25. Bus SA. Priorities in offloading the diabetic foot. Diabetes Metab Res Rev. 2012;28:54-9.

26. Paton JS, Stenhouse EA, Bruce G, Zahra D, Jones RB. A comparison of customised and prefabricated insoles to reduce risk factors for neuropathic diabetic foot ulceration: a participant-blinded randomised controlled trial. J Foot Ankle Res. 2012;5(1):1-11.
27. Lavery LA, Hunt NA, LaFontaine J, Baxter CL, Ndip A, Boulton AJ. Diabetic Foot Prevention: A neglected opportunity in high-risk patients. Diabetes Care. 2010;33(7):1460-2.

28. Ulbrecht JS, Hurley T, Mauger DT, Cavanagh PR. Prevention of recurrent foot ulcers with plantar pressurebased in-shoe orthoses: the CareFUL prevention multicenter randomized controlled trial. Diabetes Care. 2014;37(7):1982-9.

29. Amaral Jr AH, Amaral LA, Bastos MG, Nascimento LC, Alves MJ, Andrade MA. Prevention of lower-limb lesions and reduction of morbidity in diabetic patients. Rev Bras Ortop. 2014;49(5):482-7.

30. Policarpo NS, Moura JRA, Melo Jr EB, Almeida PC, Macêdo SF, Silva ARV. Knowledge, attitudes and practices for the prevention of diabetic foot. Rev Gaucha Enferm. 2014;35(3):36-42.

31. Ren M, Yang C, Lin DZ, Xiao HS, Mai LF, Guo YC, et al. Effect of intensive nursing education on the prevention of diabetic foot ulceration among patients with high-risk diabetic foot: a follow-up analysis. Diabetes Technol Ther. 2014;16(9):576-81.

Received in $05 / 20 / 2014$ Recebido em 20/05/2014

Approved in 10/15/2015 Aprovado em 15/10/2015 